most of the surgeons' instrument-makers (in the sale of which I have no interest, direct or indirect), will, I think, be found, from the material and shape, a convenient and efficient instrument, and may be used for injections of any kind. I have the honour to be, Sir, your obedient servant,

Sackrille-street, Dce. 22, 1835.

Gi:o. J上WerL.

\section{OBSTRUCHION OF THE NOSTRIL.}

\section{To the Editor of TuE LANCET.}

SrR,-I shall feel obliged if you will insert the following letter, and the remarks which I have subjoined to it, in your journal. The letter is addressed to me as the history of his case, by a patient. I am, Sir, your obedient servant,

Southampton-street, Dec. 14, 1835 .

\section{S. Plumbe.}

"Dear Sir,-As it appears that my case may possibly be instructive, I beg to hand you its history up to the time at which I consulted you. Previous to the attack which it describes, I had served during twonty-four year's in India, and bad never experienced severe illness of any kind.

"Shortly after a trip to Brighton, in August, 1834, I experienced a sensation of cold in my nose, with a catarrhal discharge, which soon afterwards became thick and ofiensive, causing me much annoyance. In December it became much aggravated, and in the subsequent May a partial obstruction of the right nostiil took place, and increased daily. Shortly afterwards the left nostril became similarly affected for a short time, though only at intervals. The right nostril now speedily bccame quite inpervious, and I found myself unable to draw air throngh it, or to expel air from the lungs by that passage. I experienced also great pain over the root of the nose, in the direction of the frontal sinuses.

"At about the latter end of May I consulted a surgeon at Bighton, and afterwards sought advice elsewhere, without any favourable result. I was recommended by one to use an injection of nitrate of silver, and by another to try one of tincture of kino, and a variety of other similar applications, all of which I patiently tried without effect. Other surgeons assured me that the constant sanious discharge from the nostrils, which excoriated my upper lip, and which had rendered me uncomfortable in society to an extent which $I$ am hardly able to describe-might be got rid of by treating it as a gleet affecting the mucous membrane of the nose. Accordingly I used balsam of copaiba and cubebs, both locally and internally. Subsequently $I$ was directed to use the golden ointment, and to thrust it up the nostril by means of a camel-hair pencil; and, as a last resource, to give a trial to the injection of chloride of soda; and, finally, with the hope that the disease really existed in the antrum, $I$ had made up $m y$ mind to the extraction of a molar tooth. Sea-side leisure and pursuits did me no good, cither as regarded my general health or the local affection. I am, your obedient servant,

"To S. Plumbe, Esq."

Remarks.-The case of this gentleman is, so far as my experience goes, one which the profession will consider rather singular and instructive, for although suffering for solong a period, the sequel is, that by the most simple meaus he has been restored to a state of perfect health, in the course of a few days. On examining the nasal passages, $I$ found the right perfectly closed by the contact of the Schneiderian membrane at the point of union of the vomer with the cartilage and the ala, with the ossa nasi, a fissure presenting itsclf there, instead of the open nostril. A probe was introduced on the first day, with some pain. On the seccnd day a small piedget of lint was passed through an eyed probe, and introduced, with a little pain, and some blood was discharged. The quantity of lint was increased from day to day, and, finally, the probe reached the throat, and gave the opportunity of applying the black lotion to a part of the nlcerated surface. The day after, the probe passed into the throat, and, to use the patient's expression, "hurt the root of his tongue." He could then pass a little air, by great exertion, through the nostril, and some minute flakes of curdy matter were blown out. The sanious discharge continued for two or three days, the nostril being still half obstructed, when the patent, by a forcible effort, expelled a large mass of curdy matter, which I take to be the inspissated pus, - the ulcerated surface having been pouring out a healthy secretion of matter, but the passage before and behind having been so closed as to prevent the egress of any but its most fiuid parts. Whether this view of the case be correct or not, a very large lump of the substance described was blown out, with little effort, into the patient's handkerchief, and he recorered within a fortnight, by the application of the black lotion, with a camel hair pencil. The right nostril is now even larger than the left, and the patient's health is better than it has been since the first attack.-S. $P$. 